\title{
Resveratrol and exercise (Review)
}

\author{
SALTUK BUGRA BALTACI, RASIM MOGULKOC and ABDULKERIM KASIM BALTACI
}

Department of Physiology, Faculty of Medicine, Selçuk University, Konya 42031, Turkey

Received August 26, 2016; Accepted September 30, 2016

DOI: 10.3892/br.2016.777

\begin{abstract}
Although it is recommended for a healthy lifestyle, moderate exercise is known to lead to oxidative stress, inflammation and muscle injury. Hence there are efforts to develop dietary strategies to counter the oxidative stress caused by physical activity. Recently, there has been an interest in the capability of resveratrol (RES) to modulate physical performance and prevent oxidative stress. Despite the inconsistency among reports regarding the topic, it has been suggested that RES delays fatigue by hindering lipid peroxidation. It is hypothesized that RES administration produces favorable effects on hepatic cell rejuvenation, exerts a regulatory effect on glucose metabolism, and preserves liver glycogen reserves that are diminished during physical activity. Consequently, there is a growing interest in the association between RES and exercise. The aim of the current review is to interpret the association between RES and exercise.
\end{abstract}

\section{Contents}

1. Introduction

2. Resveratrol metabolism

3. Resveratrol transport to tissues

4. Resveratrol excretion

5. Resveratrol and exercise

6. Resveratrol and exercise in experimental animals

7. Resveratrol in muscle tissue and exercise

8. Resveratrol and exercise in humans

9. Antioxidant effect of resveratrol in exercise

10. Conclusion

\section{Introduction}

The notion of nutrition has extended beyond its contribution to survival and regulation of food intake to assume a role

Correspondence to: Dr Rasim Mogulkoc, Department of Physiology, Faculty of Medicine, Selçuk University, Konya 42031, Turkey

E-mail: rasimmogulkoc@yahoo.com

Key words: resveratrol, metabolism, exercise in the prevention and treatment of diseases. Polyphenols are compounds that are synthesized by plants and have a wide variety of functions ranging from defense to pollination. Recently, these compounds have become of increasing interest in medical research. Within this group, the most commonly evaluated polyphenol has been resveratrol (RES), found in grapes and berries (3,5,4-trihydroxy-stilbene) (1). It is naturally present in grapes and various types of food and beverage, including red wine (2). RES (trans-3,4',5-trihidroksistilben) is produced by plants in response to different stress conditions and infections (3). It is found in assorted types of plants, such as strawberries, grapes, peanuts and pine; with the skin of fresh grapes containing 50-100 $\mu \mathrm{g} / \mathrm{g}$ wet-weight RES (4). Chemically, RES, a non-steroid compound $\left(\mathrm{C}_{14} \mathrm{H}_{12} \mathrm{O}_{3}\right)$ exerts an estrogen-like biological activity.

RES is usually found in a glycosylated or conjugate form in plants. It has been demonstrated that glycosylation protects compounds against impairment and increases gastrointestinal absorption (5). Following oral administration, RES is metabolized to water-soluble forms, including RES-3-O glucuronide and RES-3-O sulfate, by liver phase II drug-metabolizing enzymes. As the more dominant forms, which are excreted through the urine, these metabolites have longer serum half-lives than the main compound, RES (6). However, the efficiency and bioavailability of these RES metabolites remain unknown (7). The absorption of orally administered RES is more effective than that of other known polyphenols, quercetin and catechin (8). Recently, numerous pharmacological activities of RES (anti-diabetic, -oxidative, -inflammatory, -cancerous and -asthmatic, and pain killing) have been elucidated through in vitro and in vivo studies (3). Additionally, RES is a major activator of the protein and gene family of sirtuins (SIRTs; silent information regulators) (9). RES increases energy use by activating the SIRT1 signaling pathway and, hence, reinforcing mitochondrial function. Silent, but significant regulators of metabolism, cancer, aging and longevity, SIRTs are significantly associated with signal transduction pathways that are linked to stress (10).

\section{RES metabolism}

When consumed by healthy individuals, RES, which has low bioavailability, reaches its peak level in the plasma within 30-60 min (6), and accumulates in organs, such as the heart, liver and kidneys (11). It has been established that RES administered to rats reached its maximum concentration at $60 \mathrm{~min}$ in the plasma and kidneys, $30 \mathrm{~min}$ in the liver, and $120 \mathrm{~min}$ in the 
heart (12). Additionally, RES is modified by the glucuronidation reaction in liver microsomes (13). RES, which is rapidly absorbed and transferred to the tissues, is primarily excreted in the urine (12). The majority of RES is absorbed by the jejunum and a smaller quantity by the ileum (14). It is found in dietary products in cis and trans forms, and its glycosylated form is 3-O- $\beta$-D-glucoside. Preventing the enzymatic oxidation of RES, glycosylation preserves the biological efficiency of RES, and enhances its stability and bioavailability. As the intestinal cells absorb only non-glycosylated RES, glycosidases are required in the absorption process. The relative ratio between glycosylated and non-glycosylated resveratrol in food regulates its absorption rate. There are two signaling pathways associated with the transfer of trans-piceid to enterocytes: The first signaling pathway is via lactase phlorizin hydrolase found on the apical membrane. It is released to the lumen as non-glycosylated trans-RES and subsequently diffuses to the luminal side. The second signaling pathway is the destruction of glycosides by cytosolic $\beta$-glucosidase after passing through the brush border membrane by sodium-dependent glucose transporter 1. After de-glycosylation, trans-RES is formed from trans-piceid. Trans-RES is further metabolized in erythrocytes, forming a novel compound, which is a glucuronide conjugate. The major glucuronate is the trans-RES-3-O- $\beta$-glucuronide. This glucuro-conjugate is released from the enterocytes into the intestinal lumen (15).

Results from rat studies demonstrated that the half-life of orally administered RES in the circulation varies between 12 and $15 \mathrm{~min}$. In these studies, RES was administered to the rats at doses of $2 \mathrm{mg} / \mathrm{kg}$ (16) and $50 \mathrm{mg} / \mathrm{kg}$ (17) and at a dose of $20 \mathrm{mg} / \mathrm{kg}$ to mice (18) through the intragastric route, and the peak concentration values in the plasma were found to be 0.5, 1.2 and $6.6 \mu \mathrm{M}$, respectively. Rat and mouse studies have demonstrated that RES is absorbed well, and is rapidly transformed to glucuronide and sulfate conjugates in the epithelial cells of the liver and intestines $(8,19,20)$. When labelled RES is orally administered to rats, $50-75 \%$ of the dose is absorbed. The peak plasma concentration of RES glucuronide was found to be $105 \mu \mathrm{M}$ and it was shown that RES was strongly subject to enterohepatic circulation (8). In perfused rat small intestines, $16.8 \%$ of RES was found as RES glucuronide, $3.4 \%$ as RES sulfate, and $0.3 \%$ as free RES (18). It was demonstrated that following the perfusion of $200 \mu \mathrm{M}$ RES in isolated rat small intestines, the majority of the RES was converted to glucuronide conjugate and entered circulation (21). Similarly, RES was shown to be converted to glucuronide and sulfate conjugates in human and rodent liver and intestine cells (20). According to these studies, it appears that RES is absorbed in considerable quantities through the gastrointestinal tract in rats and mice, and is metabolized in the liver and intestines through conjugation. When administered orally at a high dose (such as $50 \mathrm{mg} / \mathrm{kg}$ ) to rats, the peak concentration of unmetabolized RES drops to $<10 \mu \mathrm{M}$ and it is eliminated very rapidly. Conversely, the conjugates of RES reach higher plasma levels when compared with RES (17).

In a study with male volunteers aged 30-50 years, Meng et al (22) administered a group $0.03,0.5$ or $1 \mathrm{mg} / \mathrm{kg}$ RES dissolved in whisky. Another group was administered 200, 400, 600 and 12,00 ml grape juice containing 0.16/100 $\mathrm{ml} \mathrm{RES}$, and RES was identified in the urine samples in the group given just grape juice. It was shown that at the dose of $0.03 \mathrm{mg} / \mathrm{kg}$, the majority of the RES was eliminated within 2-3 h, while at the dose of $1 \mathrm{mg} / \mathrm{kg}$, RES elimination took 7-10 h (22). Since its water solubility is quite low, RES has to be either conjugated or bound to proteins to be found in high concentrations in the serum (23). Albumin is one of the plasma proteins that carry RES (24). In addition, plasma RES was shown to interact with lipoproteins (25). In order to investigate the toxic effects of RES, Sprague-Dawley rats were orally administered $20 \mathrm{mg} / \mathrm{kg}$ RES for 28 days and hematologic, biochemical and histopathologic analyses were conducted. The study found that alanine transaminase and aspartate aminotransferase enzyme levels, which are indicators of hepatic toxicity, did not change as a result of RES administration; similarly, the hematologic, biochemical and histopathological parameters remained unchanged (26).

\section{RES transport to tissues}

The hydrophilic conjugation of RES facilitates its transfer to blood, its distribution in the body and its expression. RES and its metabolites are filtered from the blood by the liver and gall bladder, discharged to the intestines with bile, and subsequently re-absorbed. RES is found in the colon shortly after its oral administration; however, its distribution to tissues takes a couple of hours. RES is conjugated with glucuronic acid in the liver, and with sulfates in the liver and duodenum (6).

\section{RES excretion}

The time of excretion depends on the plasma concentration of RES. However, there is no correlation between the quantity produced and the quantity excreted. A particularly small quantity of non-glycosylated RES is present in the urine. Although it is found predominantly in its natural form in the kidneys, the urine primarily contains its conjugated form (14).

\section{RES and exercise}

In addition to dietary habits, physical exercise is considered to be a major component of a healthy lifestyle. Moderate exercise has been demonstrated to be useful in the prevention of primary and secondary diseases, including cardiovascular diseases (27), type II diabetes (28), metabolic syndrome (29) and neurodegenerative diseases, such as Alzheimer's $(30,31)$. The term hormesis has been proposed to explain the phenomenon of surviving exposure to small concentrations of toxic substances and adapting to them (32). The adaptive response that the metabolism produces to physical exercise is explained in this framework. In response to the increase in free radical production resulting from intense physical exercise, the metabolism activates its antioxidant system (33). Commonly accepted to be a calorie-limiting factor (34), RES affects adaptations in the $\mathrm{O}_{2}$ transport system to meet the increased $\mathrm{O}_{2}$ requirements in exercise. In many cases, RES activates molecule pathways during exercise $(35,36)$ and produces a performance enhancing effect (37). Conversely, human studies demonstrate that RES curbs the beneficial effects of exercise in certain groups of patients, such as those with cardiovascular disease $(38,39)$. Consequently, the effects of RES on exercise are debatable and require further investigation. 


\section{RES and exercise in experimental animals}

An active lifestyle is regarded as a major component of healthy aging. Since RES was claimed to have a performance-boosting effect in exercise, it has been assumed that RES may contribute to maintaining health in aging and increasing the quality of life $(35,36)$. Accordingly, RES was shown to increase endurance in exercise $(40)$ and longevity $(41,42)$ in an old mouse model. It is clear that in these events, RES therapy activates skeletal muscle function to a great extent (43). To illustrate, when sedentary mice fed on a high-fat diet were administered RES, their skeletal muscle stamina and strength increased $(41,42)$. Different reports have shown that RES prevents muscle breakdown (44), recovery of atrophic muscle mass in mice (45) and improves muscle function in muscular dystrophy in mice (46). Furthermore, it has been reported that RES increased exercise capabilities and sketletal muscular endurance $(20,37)$. Consistently, RES was shown to elevate the muscle strength and aerobic endurance in rats specifically bred for types of exercise requiring stamina (47). Notably, in addition to its beneficial effects on exercise (48), RES was shown to exert significant effects on the heart tissue in two different rodent models. Consequently, when administered in combination with regular exercise (37), RES is proposed to have additional beneficial effects on the heart and skeletal muscle. One-month administration of RES (15 mg/kg/day) together with swimming exercise in old rats (age, 18 months) demonstrated that RES had a positive impact on the cardiac functions of old rats via activation of the SIRT1 signaling pathway (49). It was reported that $100 \mathrm{mg} / \mathrm{kg}$ RES administration to young mice (age, 4-5 months) with muscular dystrophy for 8 weeks improved muscle functions, although oxidative parameters remained unchanged (46). A notable finding, with regard to the association between aging and RES, was that even short-term administration of RES was demonstrated to elevate antioxidant activity and the proteins associated with it in old mice (50). Similarly, RES therapy prevented bone loss associated with the skeletal system and aging in old male rats (51). In contrast to the above-mentioned results, it has been reported that RES may not always have beneficial effects in all rodent models. For example, RES administration did not improve endurance in the case of a single-session exercise in genetically obese mice (52). Similarly, it was reported that RES administration did not boost treadmill stamina over the 12 -week training period in mice specifically bred for low-capacity exercise types (47). In contrast to exercise, RES supplementation did not affect peritoneal macrophages in mice (53). An overall evaluation of these results (all of which are animal experiments) indicates that the performance-boosting effects of RES in exercise are inconsistent.

\section{Resveratrol in muscle tissue and exercise}

During physical exercise muscle tissues require large quantities of energy (in the form of ATP) to fulfill their contraction functions. The required energy (ATP) is produced by muscle mitochondria through oxidative phosphorylation. Thus, a useful adaptation of the muscle to exercise training is increased mitochondrial function and content $(54,55)$. As with exercise, RES enables mitochondrial biogenesis in the skeletal muscle and cardiac tissues $(56,57)$, as well as in endothelial cells (58). Metabolic and cardiovascular diseases $(59,60)$, and aging restrict the exercise capacity of muscle tissues by diminishing their mitochondrial function and content. However, exercise training and RES enhance mitochondrial function and content in aging, and prevent the aging-associated reduction in the mitochondrial content of the skeletal muscle $(61,62)$.

\section{Resveratrol and exercise in humans}

An examination of the effects of RES or placebo together with high-intensity aerobic exercise in physically inactive, but healthy men, aged between 60 and 75 years showed that exercise reduced oxidative stress and inflammation, while increasing muscular endurance and maximal oxygen intake in the skeletal muscle in the placebo group $(38,39)$. Notably, the positive exercise-induced effects on the concerned parameters were not observed in the RES group $(38,39)$. However, it should be noted that the dose of RES used in the study $(3.1 \mathrm{mg} / \mathrm{kg} /$ day $)(38,39)$ was significantly lower than the RES dose bringing about favorable effects in animal studies $(10 \mathrm{mg} / \mathrm{kg} /$ day) $(37,47)$. Arguably, the most significant study regarding the association between RES and exercise is one involving athletes who ran in the London marathon. The study investigated the effects of administration of $600 \mathrm{mg} /$ day RES or placebo to athletes during the week prior to the run on the inflammatory response and muscle injury. No significant difference was found between the RES and placebo groups (63). Similarly, daily administration of $150 \mathrm{mg}$ RES for four weeks did not alter performance adaptation and muscle function response to low-dose high intensity exercise (3 days per week) (64). Olesen et al (39) reported that exercise improved metabolic functions of muscles in older men (aged 60-72 years), while administration of $250 \mathrm{mg}$ RES daily over a period of 8 weeks did not produce a positive impact. Likewise, Voduc et al (2) showed that RES supplementation did not alter exercise duration and aerobic capacity, and that despite the slight decrease in fasting blood glucose and slight (not statistically significant) increase in liver enzymes, the results were within the normal range; while total blood parameters, immunity parameters, and liver functions remained unaffected by RES. Consequently, unlike animal studies, the results of studies investigating the association between RES and exercise in humans are not promising.

\section{Antioxidant effect of RES in exercise}

Although it is recommended to contribute to a healthy lifestyle, moderate physical exercise leads to tissue damage (32). Therefore, efforts to develop dietary strategies against oxidative stress caused by physical activity are being made (33). Recently, there has been a growing interest in investigating the potential of RES to modulate physical performance and prevent oxidative stress (34). RES was shown to prevent lipid peroxidation in mice that were 12-months-old (40). Dal-Ros et al (65) also presented similar results. In a study involving 14 athletes, RES supplementation was shown to inhibit the lipid peroxidation caused by exercise (66). Furthermore, regular exercise training improves vascular functions by reducing 
reactive oxygen species (67). Exercise training results in an increased antioxidant activity $(68,69)$. Similar to exercise, RES increases the expression of these antioxidant enzymes in endothelial $(70,71)$ and smooth muscle (69) cells. Recently, RES was shown to reduce vascular damage by elevating superoxide dismutase 2, mitochondrial expression in isolated vessels of hypertensive patients (72). Unlike exercise, RES eliminates reactive oxygen species $(71,73)$. Although SIRT1 overexpression was shown to reduce the mitochondrial oxidative stress in endothelial cells, RES also elevates the levels of SIRT1, in a dose-dependent manner, which may lead to a marked benefit in exercise $(74,75)$.

Besides preventing ischemic attacks $(76,77)$, regular physical activity reduces the infarct tendency, by conditioning the heart for ischemic attacks, and encourages post-ischemic functional recovery (78). It has been shown that pharmacological doses of RES exerts a regenerative affect on heart function in mice $(79,80)$. As a result, RES has curative affect on myocardial function due to reduced free radical production $(81,82)$ and increased antioxidant activity $(83,84)$. Thus, it has been concluded that RES is a crucial protector of the heart during post-ischemic recovery.

\section{Conclusion}

Various studies examining the association between RES and exercise have been performed at the Physiology Department of Selçuk University's School of Medicine. One of these is the study by Duran et al (85). The study examined the effect of RES supplementation on plasma leptin and liver glycogen levels in rats that were subjected to an acute swimming exercise regime. In the study, RES supplementation to rats subjected to the acute swimming exercise regime prevented the reduction in liver glycogen resulting from exercise. This result indicates that RES exerts a protective effect on liver glycogen. Arslangil (86) investigated how RES supplementation to rats subjected to an acute swimming exercise regime affected element metabolism in the blood and tissues. The study demonstrated that swimming exercise and RES supplementation produced changes in the element distribution in the rat blood and tissues. Furthermore, it was demonstrated that RES supplementation exerts a protective and/or regulatory effect on bone metabolism, independent of exercise. Thus, examination of these studies regarding the association between RES and exercise indicates that the current results of published studies are inconsistent, and a standard is yet to be established regarding the association between dose and duration in RES administration. Furthermore, due to its positive effects on muscle functions, antioxidant activity, liver glycogen, carbohydrate metabolism and bone metabolism, RES is undeniably correlated with exercise. However, future studies are required to reveal the effects of RES on exercise.

\section{References}

1. Raj P, Louis XL, Thandapilly SJ, Movahed A, Zieroth S and Netticadan T: Potential of resveratrol in the treatment of heart failure. Life Sci 95: 63-71, 2014.

2. Voduc N, la Porte C, Tessier C, Mallick R and Cameron DW: Effect of resveratrol on exercise capacity: A randomized placebo-controlled crossover pilot study. Appl Physiol Nutr Metab 39: 1183-1187, 2014.
3. Wu RE, Huang WC, Liao CC, Chang YK, Kan NW and Huang CC: Resveratrol protects against physical fatigue and improves exercise performance in mice. Molecules 18: 4689-4702, 2013.

4. Joe AK, Liu H, Suzui M, Vural ME, Xiao D and Weinstein IB: Resveratrol induces growth inhibition, S-phase arrest, apoptosis, and changes in biomarker expression in several human cancer cell lines. Clin Cancer Res 8: 893-903, 2002.

5. Regev-Shoshani G, Shoseyov O, Bilkis I and Kerem Z: Glycosylation of resveratrol protects it from enzymic oxidation. Biochem J 374: 157-163, 2003.

6. Walle T, Hsieh F, DeLegge MH, Oatis JE Jr and Walle UK: High absorption but very low bioavailability of oral resveratrol in humans. Drug Metab Dispos 32: 1377-1382, 2004.

7. Baur JA and Sinclair DA: Therapeutic potential of resveratrol: The in vivo evidence. Nat Rev Drug Discov 5: 493-506, 2006.

8. Soleas GJ, Yan J and Goldberg DM: Ultrasensitive assay for three polyphenols (catechin, quercetin and resveratrol) and their conjugates in biological fluids utilizing gas chromatography with mass selective detection. J Chromatogr B Biomed Sci Appl 757: 161-172, 2001.

9. Moynihan KA, Grimm AA, Plueger MM, Bernal-Mizrachi E, Ford E, Cras-Méneur C, Permutt MA and Imai S: Increased dosage of mammalian Sir2 in pancreatic beta cells enhances glucose-stimulated insulin secretion in mice. Cell Metab 2: 105-117, 2005.

10. Milne JC, Lambert PD, Schenk S, Carney DP, Smith JJ, Gagne DJ, Jin L, Boss O, Perni RB, Vu CB, et al: Small molecule activators of SIRT1 as therapeutics for the treatment of type 2 diabetes. Nature 450: 712-716, 2007.

11. Goldberg DM, Yan J and Soleas GJ: Absorption of three wine-related polyphenols in three different matrices by healthy subjects. Clin Biochem 36: 79-87, 2003.

12. Bertelli AA, Giovannini L, Stradi R, Bertelli A and Tillement JP: Plasma, urine and tissue levels of trans- and cis-resveratrol (3,4,5-trihydroxystilbene) after short-term or prolonged administration of red wine to rats. Int J Tissue React 18: 67-71, 1996.

13. Aumont V, Krisa S, Battaglia E, Netter P, Richard T, Mérillon JM, Magdalou J and Sabolovic N: Regioselective and stereospecific glucuronidation of trans- and cis-resveratrol in human. Arch Biochem Biophys 393: 281-289, 2001.

14. Signorelli P and Ghidoni R: Resveratrol as an anticancer nutrient: Molecular basis, open questions and promises. J Nutr Biochem 16: 449-466, 2005.

15. Henry-Vitrac C, Desmoulière A, Girard D, Mérillon JM and Krisa S: Transport, deglycosylation, and metabolism of trans-piceid by small intestinal epithelial cells. Eur J Nutr 45: 376-382, 2006

16. Juan ME, Vinardell MP and Planas JM: The daily oral administration of high doses of trans-resveratrol to rats for 28 days is not harmful. J Nutr 132: 257-260, 2002.

17. Marier JF, Vachon P, Gritsas A, Zhang J, Moreau JP and Ducharme MP: Metabolism and disposition of resveratrol in rats: Extent of absorption, glucuronidation, and enterohepatic recirculation evidenced by a linked-rat model. J Pharmacol Exp Ther 302: 369-373, 2002.

18. Asensi M, Medina I, Ortega A, Carretero J, Baño MC, Obrador E and Estrela JM: Inhibition of cancer growth by resveratrol is related to its low bioavailability. Free Radic Biol Med 33: 387-398, 2002.

19. Vitrac X, Desmoulière A, Brouillaud B, Krisa S, Deffieux G, Barthe N, Rosenbaum J and Mérillon JM: Distribution of [14C]-trans-resveratrol, a cancer chemopreventive polyphenol, in mouse tissues after oral administration. Life Sci 72: 2219-2233, 2003.

20. Yu C, Shin YG, Chow A, Li Y, Kosmeder JW, Lee YS, Hirschelman WH, Pezzuto JM, Mehta RG and van Breemen RB: Human, rat, and mouse metabolism of resveratrol. Pharm Res 19: 1907-1914, 2002.

21. Kuhnle G, Spencer JP, Chowrimootoo G, Schroeter H, Debnam ES, Srai SK, Rice-Evans C and Hahn U: Resveratrol is absorbed in the small intestine as resveratrol glucuronide. Biochem Biophys Res Commun 272: 212-217, 2000.

22. Meng X, Maliakal P, Lu H, Lee MJ and Yang CS: Urinary and plasma levels of resveratrol and quercetin in humans, mice, and rats after ingestion of pure compounds and grape juice. J Agric Food Chem 52: 935-942, 2004.

23. Belguendouz L, Fremont L and Linard A: Resveratrol inhibits metal ion-dependent and independent peroxidation of porcine low-density lipoproteins. Biochem Pharmacol 53: 1347-1355, 1997. 
24. Jannin B, Menzel M, Berlot JP, Delmas D, Lançon A and Latruffe N: Transport of resveratrol, a cancer chemopreventive agent, to cellular targets: Plasmatic protein binding and cell uptake. Biochem Pharmacol 68: 1113-1118, 2004.

25. Belguendouz L, Frémont L and Gozzelino MT: Interaction of transresveratrol with plasma lipoproteins. Biochem Pharmacol 55: 811-816, 1998.

26. Juan ME, Buenafuente J, Casals I and Planas JM: Plasmatic levels of trans-resveratrol in rats. Food Res Int 35: 195-199, 2002

27. Daviglus ML, Lloyd-Jones DM and Pirzada A: Preventing cardiovascular disease in the 21st Deweerdt S. Prevention: Activity is the best medicine. Nature 475: 16-17, 2011.

28. Bertram MY, Lim SS, Barendregt JJ and Vos T: Assessing the cost-effectiveness of drug and lifestyle intervention following opportunistic screening for pre-diabetes in primary care. Diabetologia 53: 875-881, 2010.

29. Church T: Exercise in obesity, metabolic syndrome, and diabetes Prog Cardiovasc Dis 53: 412-418, 2011.

30. Deweerdt S: Prevention: Activity is the best medicine. Nature 475: S16-S17, 2011.

31. Hurley BF, Hanson ED and Sheaff AK: Strength training as a countermeasure to aging muscle and chronic disease. Sports Med 41: 289-306, 2011

32. Malaguti M, Angeloni C and Hrelia S: Polyphenols in exercise performance and prevention of exercise-induced muscle damage. Oxid Med Cell Longev 2013: 825928, 2013.

33. Ji LL, Gomez-Cabrera MC and Vina J: Role of free radicals and antioxidant signaling in skeletal muscle health and pathology. Infect Disord Drug Targets 9: 428-444, 2009.

34. Dolinsky VW and Dyck JR: Calorie restriction and resveratrol in cardiovascular health and disease. Biochim Biophys Acta 1812: 1477-1489, 2011.

35. Mercken EM, Carboneau BA, Krzysik-Walker SM and de Cabo R: Of mice and men: The benefits of caloric restriction, exercise, and mimetics. Ageing Res Rev 11: 390-398, 2012

36. Schrauwen P and Timmers S: Can resveratrol help to maintain metabolic health? Proc Nutr Soc 73: 271-277, 2014.

37. Dolinsky VW, Jones KE, Sidhu RS, Haykowsky M, Czubryt MP, Gordon T and Dyck JR: Improvements in skeletal muscle strength and cardiac function induced by resveratrol contribute to enhanced exercise performance in rats. J Physiol 590: 2783-2799, 2012.

38. Gliemann L, Schmidt JF, Olesen J, Biens $\varnothing$ RS, Peronard SL, Grandjean SU, Mortensen SP, Nyberg M, Bangsbo J, Pilegaard $\mathrm{H}$, et al: Resveratrol blunts the positive effects of exercise training on cardiovascular health in aged men. J Physiol 591: 5047-5059, 2013.

39. Olesen J, Gliemann L, Biens $\varnothing$ R, Schmidt J, Hellsten Y and Pilegaard $\mathrm{H}$ : Exercise training, but not resveratrol, improves metabolic and inflammatory status in skeletal muscle of aged men. J Physiol 592: 1873-1886, 2014.

40. Murase T, Haramizu S, Ota N and Hase T: Suppression of the aging-associated decline in physical performance by a combination of resveratrol intake and habitual exercise in senescence-accelerated mice. Biogerontology 10: 423-434, 2009.

41. Baur JA, Pearson KJ, Price NL, Jamieson HA, Lerin C, Kalra A Prabhu VV, Allard JS, Lopez-Lluch G, Lewis K, et al: Resveratrol improves health and survival of mice on a high-calorie diet. Nature 444: 337-342, 2006

42. Lagouge M, Argmann C, Gerhart-Hines Z, Meziane H, Lerin C, Daussin F, Messadeq N, Milne J, Lambert P, Elliott P, et al: Resveratrol improves mitochondrial function and protects against metabolic disease by activating SIRT1 and PGC-1alpha. Cell 127: 1109-1122, 2006.

43. Marchal J, Pifferi F and Aujard F: Resveratrol in mammals: Effects on aging biomarkers, age-related diseases, and life span Ann N Y Acad Sci 1290: 67-73, 2013.

44. Momken I, Stevens L, Bergouignan A, Desplanches D, Rudwill F Chery I, Zahariev A, Zahn S, Stein TP, Sebedio JL, et al: Resveratrol prevents the wasting disorders of mechanical unloading by acting as a physical exercise mimetic in the rat. FASEB J 25: 3646-3660, 2011.

45. Bennet D and Kim S: Effects of agmatine and resveratrol on RGC-5 cell behavior under light stimulation. Environ Toxicol Pharmacol 38: 84-97, 2014

46. Gordon BS, Delgado-Diaz DC, Carson J, Fayad R, Wilson LB and Kostek MC: Resveratrol improves muscle function but not oxidative capacity in young mdx mice. Can J Physiol Pharmacol 92: 243-251,2014.

47. Hart N, Sarga L, Csende Z, Koltai E, Koch LG, Britton SL, Davies KJ, Kouretas D, Wessner B and Radak Z: Resveratrol enhances exercise training responses in rats selectively bred for high running performance. Food Chem Toxicol 61: 53-59, 2013.
48. Dolinsky VW,Rogan KJ,Sung MM,Zordoky BN,Haykowsky MJ, Young ME, Jones LW and Dyck JR: Both aerobic exercise and resveratrol supplementation attenuate doxorubicin-induced cardiac injury in mice. Am J Physiol Endocrinol Metab 305: E243-E253, 2013.

49. Lin CH, Lin CC, Ting WJ, Pai PY, Kuo CH, Ho TJ, Kuo WW, Chang $\mathrm{CH}$, Huang CY and Lin WT: Resveratrol enhanced FOXO3 phosphorylation via synergetic activation of SIRT1 and PI3K/Akt signaling to improve the effects of exercise in elderly rat hearts. Age (Dordr) 36: 9705, 2014

50. Tung BT, Rodríguez-Bies E, Ballesteros-Simarro M, Motilva V, Navas P and López-Lluch G: Modulation of endogenous antioxidant activity by resveratrol and exercise in mouse liver is age dependent. J Gerontol A Biol Sci Med Sci 69: 398-409, 2014.

51. Durbin SM, Jackson JR, Ryan MJ, Gigliotti JC, Alway SE and Tou JC: Resveratrol supplementation preserves long bone mass, microstructure, and strength in hindlimb-suspended old male rats. J Bone Miner Metab 32: 38-47, 2014.

52. Mayers JR, Iliff BW and Swoap SJ: Resveratrol treatment in mice does not elicit the bradycardia and hypothermia associated with calorie restriction. FASEB J 23: 1032-1040, 2009.

53. Park HG, Lee YR, Jun JK and Lee WL: Exercise training is more effective than resveratrol supplementation on alleviation of inflammation in peritoneal macrophages of high fat diet mice. J Exerc Nutrition Biochem 18: 79-87, 2014.

54. Jacobs RA and Lundby C: Mitochondria express enhanced quality as well as quantity in association with aerobic fitness across recreationally active individuals up to elite athletes. J Appl Physiol 1985 114: 344-350, 2013.

55. Holloszy JO and Coyle EF: Adaptations of skeletal muscle to endurance exercise and their metabolic consequences. J Appl Physiol Respir Environ Exerc Physiol 56: 831-838, 1984.

56. Biala A, Tauriainen E, Siltanen A, Shi J, Merasto S, Louhelainen M, Martonen E, Finckenberg P, Muller DN and Mervaala E: Resveratrol induces mitochondrial biogenesis and ameliorates Ang II-induced cardiac remodeling in transgenic rats harboring human renin and angiotensinogen genes. Blood Press 19: 196-205, 2010.

57. Rimbaud S, Ruiz M, Piquereau J, Mateo P, Fortin D, Veksler V, Garnier A and Ventura-Clapier R: Resveratrol improves survival, hemodynamics and energetics in a rat model of hypertension leading to heart failure. PLoS One 6: e26391, 2011.

58. Csiszar A, Labinskyy N, Pinto JT, Ballabh P, Zhang H, Losonczy G, Pearson K, de Cabo R, Pacher P, Zhang C, et al: Resveratrol induces mitochondrial biogenesis in endothelial cells. Am J Physiol Heart Circ Physiol 297: H13-H20, 2009.

59. Boudina S, Sena S, O'Neill BT, Tathireddy P, Young ME and Abel D: Reduced mitochondrial oxidative capacity and increased mitochondrial uncoupling impair myocardial energetics in obesity. Circulation 112: 2686-2695, 2005.

60. Pierce GN and Dhalla NS: Heart mitochondrial function in chronic experimental diabetes in rats. Can J Cardiol 1: 48-54, 1985.

61. Joseph AM, Malamo AG, Silvestre J, Wawrzyniak N, Carey-Love S, Nguyen LM, Dutta D, Xu J, Leeuwenburgh C and Adhihetty PJ: Short-term caloric restriction, resveratrol, or combined treatment regimens initiated in late-life alter mitochondrial protein expression profiles in a fiber-type specific manner in aged animals. Exp Gerontol 48: 858-868, 2013.

62. Broskey NT, Greggio C, Boss A, Boutant M, Dwyer A, Schlueter L, Hans D, Gremion G, Kreis R, Boesch C, et al: Skeletal muscle mitochondria in the elderly: Effects of physical fitness and exercise training. J Clin Endocrinol Metab 99: 1852-1861, 2014

63. Laupheimer MW, Perry M, Benton S, Malliaras P and Maffulli N: Resveratrol exerts no effect on inflammatory response and delayed onset muscle soreness after a marathon in male athletes.: A randomised, double-blind, placebo-controlled pilot feasibility study. Transl Med UniSa 10: 38-42, 2014.

64. Scribbans TD, Ma JK, Edgett BA, Vorobej KA, Mitchell AS, Zelt JG, Simpson CA, Quadrilatero J and Gurd BJ: Resveratrol supplementation does not augment performance adaptations or fibre-type-specific responses to high-intensity interval training in humans. Appl Physiol Nutr Metab 39: 1305-1313, 2014.

65. Dal-Ros S,Zoll J, Lang AL, Auger C, Keller N, Bronner C, Geny B and Schini-Kerth VB: Chronic intake of red wine polyphenols by young rats prevents aging-induced endothelial dysfunction and decline in physical performance: Role of NADPH oxidase. Biochem Biophys Res Commun 404: 743-749, 2011. 
66. McAnulty LS, Miller LE, Hosick PA, Utter AC, Quindry JC and McAnulty SR: Effect of resveratrol and quercetin supplementation on redox status and inflammation after exercise. Appl Physiol Nutr Metab 38: 760-765, 2013.

67. Radak Z, Chung HY, Koltai E, Taylor AW and Goto S: Exercise, oxidative stress and hormesis. Ageing Res Rev 7: 34-42, 2008.

68. de Moraes C, Davel AP, Rossoni LV, Antunes E and Zanesco A: Exercise training improves relaxation response and SOD-1 expression in aortic and mesenteric rings from high caloric diet-fed rats. BMC Physiol 8: 12, 2008.

69. Gu Q, Wang B, Zhang XF, Ma YP, Liu JD and Wang XZ: Chronic aerobic exercise training attenuates aortic stiffening and endothelial dysfunction through preserving aortic mitochondrial function in aged rats. Exp Gerontol 56: 37-44, 2014.

70. Spanier G, Xu H, Xia, N, Tobias S, Deng S, Wojnowski L, Forstermann $\mathrm{U}$ and $\mathrm{Li} \mathrm{H}$ : Resveratrol reduces endothelial oxidative stress by modulating the gene expression of superoxidedismutase 1 (SOD1), glutathione peroxidase 1 (GPx1) and NADPH oxidase subunit (Nox4). J Physiol Pharmacol 60: 111-116, 2009.

71. Ungvari Z, Orosz Z, Rivera A, Labinskyy N, Xiangmin Z, Olson S, Podlutsky A and Csiszar A: Resveratrol increases vascular oxidative stress resistance. Am J Physiol Heart Circ Physiol 292: H2417-H2424, 2007.

72. Carrizzo A, Puca A, Damato A, Marino M, Franco E, Pompeo F, Traficante A, Civitillo F, Santini L, Trimarco V, et al: Resveratro improves vascular function in patients with hypertension and dyslipidemia by modulating NO metabolism. Hypertension 62: 359-366, 2013.

73. Soylemez S, Sepici A and Akar F: Resveratrol supplementation gender independently improves endothelial reactivity and suppresses superoxide production in healthy rats. Cardiovase Drugs Ther 23: 449-458, 2009.

74. Kao CL, Chen LK, Chang YL, Yung MC, Hsu CC, Chen YC, Lo WL, Chen SJ, Ku HH and Hwang SJ: Resveratrol protects human endothelium from $\mathrm{H}(2) \mathrm{O}(2)$-induced oxidative stress and senescence via SirT1 activation. J Atheroscler Thromb 17: 970-979, 2010

75. Ungvari Z, Labinskyy N, Mukhopadhyay P, Pinto JT, Bagi Z, Ballabh P,Zhang C,Pacher P and Csiszar A: Resveratrol attenuates mitochondrial oxidative stress in coronary arterial endothelial cells. Am J Physiol Heart Circ Physiol 297: H1876-H1881, 2009.

76. Mittleman MA, Maclure M, ToflerGH, Sherwood JB, Goldberg RJ and Muller JE; Determinants of Myocardial Infarction Onset Study Investigators: Triggering of acute myocardial infarction by heavy physical exertion. Protection against triggering by regular exertion. N Engl J Med 329: 1677-1683, 1993.
77. Willich SN, Lewis M, Löwel H, Arntz HR, Schubert F and Schröder R; Triggers and Mechanisms of Myocardial Infarction Study Group: Physical exertion as a trigger of acute myocardial infarction. N Engl J Med 329: 1684-1690, 1993.

78. Yamashita N, Hoshida S, Otsu K, Asahi M, Kuzuya T and Hori M: Exercise provides direct biphasic cardioprotection via manganese superoxide dismutase activation. J Exp Med 189: 1699-1706, 1999

79. Kaga S, Zhan L, Matsumoto M and Maulik N: Resveratrol enhances neovascularization in the infarcted rat myocardium through the induction of thioredoxin-1, heme oxygenase-1 and vascular endothelial growth factor. J Mol Cell Cardiol 39: 813-822, 2005

80. Hung LM, Su MJ and Chen JK: Resveratrol protects myocardial ischemia-reperfusion injury through both NO-dependent and NO-independent mechanisms. Free Radic Biol Med 36: 774-781, 2004.

81. Hwang JT, Kwon DY, Park OJ and Kim MS: Resveratrol protects ROS-induced cell death by activating AMPK in H9c2 cardiac muscle cells. Genes Nutr 2: 323-326, 2008.

82. Ray PS, Maulik G, Cordis GA, Bertelli AA, Bertelli A and Das DK: The red wine antioxidant resveratrol protects isolated rat hearts from ischemia reperfusion injury. Free Radic Biol Med 27: 160-169, 1999.

83. Goh SS, Woodman OL, Pepe S, Cao AH, Qin C and Ritchie RH: The red wine antioxidant resveratrol prevents cardiomyocyte injury following ischemia-reperfusion via multiple sites and mechanisms. Antioxid Redox Signal 9: 101-113, 2007.

84. Shen M, Wu RX, Zhao L, Li J, Guo HT, Fan R, Cui Y, Wang YM, Yue SQ and Pei JM: Resveratrol attenuates ischemia/reperfusion injury in neonatal cardiomyocytes and its underlying mechanism. PLoS One 7: e51223, 2012.

85. Duran MO, Baltaci AK, Mogulkoc R, Avunduk MC and Ergene N: The effect of resveratrol supplementation on plasma leptin and liver glycogen levels in rats with acute swimming exercise. Acta Physiol (Oxf) 215 (Suppl 705): 87-87, 2015.

86. Arslangil D: The effect of resveratrol supplementation on element metabolism in blood and some tissue of rats with acute swimming exercise. Republic of Turkey Selcuk University Health Sciences Institute Master Thesis, 2010. 